[in press, Animal Biology, February 2009]

\title{
Sexual Conflict in Humans: Evolutionary Consequences of Asymmetric Parental Investment and Paternity Uncertainty
}

\author{
Aaron T. Goetz ${ }^{1}$ and Todd K. Shackelford ${ }^{2}$ \\ ${ }^{1}$ California State University, Fullerton \\ ${ }^{2}$ Florida Atlantic University
}

Send Correspondence to:

Aaron T. Goetz at agoetz@fullerton.edu 


\begin{abstract}
We argue that sexual conflict was a recurrent feature of human evolutionary history, just as it has been in every sexually reproducing species that does not practice life-long genetic monogamy. We suggest that the source of much of the conflict between men and women can be reduced to an asymmetry in reproductive biology. This asymmetry-fertilization and gestation occurring within women—produces (a) sex differences in minimum obligatory parental investment and (b) paternity uncertainty. We argue that these consequences of internal fertilization and gestation are responsible for many phenomena in humans, such as sexual coercion, commitment skepticism, sexual overperception, and a host of adaptations associated with sperm competition.
\end{abstract}

Key words: sexual conflict in humans; infidelity; paternity uncertainty; sperm competition 


\section{Introduction}

Evolution by natural selection is the centerpiece of biology, and in the last couple of decades many psychologists have recognized the value of using an evolutionary perspective to guide their work. Evolutionary psychologists attempt to understand current human thought, emotion, and behavior by careful consideration of human evolutionary history. Over our evolutionary history, humans recurrently encountered many adaptive problems that needed to be solved to survive and reproduce. Over millions of years, natural selection slowly shaped the human brain, favoring neural circuitry that was better than alternative circuitry at solving these adaptive problems of our ancestors.

To take one example, humans' current taste preference for foods high in sugar and fat is parsimoniously understood from an evolutionary psychological perspective. Our taste preference for foods high in sugar and fat evolved when such substances were not readily available in high concentrations (as they are now). These taste preferences motivated our ancestors to seek calorically dense and nutritious food, adaptive behavior in our ancestral environment. Despite the fact that this taste preference has negative health consequences today (e.g., diabetes, cardiovascular disease, obesity), we retain this evolved preference. Individuals can consciously modify their behavior to avoid food rich in sugar and fat (e.g., dieting), but individuals cannot modify their taste preference for sugar and fat.

The modern application of evolutionary principles to the study of human psychology and behavior has paved new avenues of research that were not present just 20 years ago. One of these research avenues is sexual conflict in humans. Sexual conflict occurs when the evolutionary interests of males and females diverge (Parker, 1979; Trivers, 1972). Although human mating is 
often viewed as a cooperative venture between two individuals of the opposite sex with a common reproductive goal, the evolutionary interests of human males and females are certainly asymmetrical (Buss, 1989). A review of the literature examining lifetime infidelity rates and paternal discrepancy rates indicates that humans are not a monogamous species. Infidelity rates vary depending on when, how, and to whom the question is asked, but dozens of studies document that infidelity is common, and infidelity rates in some samples exceed 50\% (see Table 1 in Koehler \& Chisholm, 2007). Paternal discrepancy rates (also known as cuckoldry rates or nonpaternity rates) reflect a key reproductive consequence of female infidelity (when men unwittingly raise children to whom they are not genetically related), and these rates_-even with the advent of modern contraception — are consistently above $0 \%$ and are as high as $30 \%$ in some samples (Anderson, 2006; Bellis et al., 2005; Cerda-Flores et al., 1999; Sasse et al., 1994).

Biologists have identified two types of sexual conflict: intralocus sexual conflict and interlocus sexual conflict (for a review, see Arqvist \& Rowe, 2005). Intralocus sexual conflict can occur between traits common to males and females on which there is opposing selection. In humans, for example, wider hips are favored in females due to childbirth (Rice \& Chippindale, 2008). Interlocus sexual conflict occurs when a trait is encoded by different genes in males and females, producing conflict in the outcome of male-female interactions. This form of conflict, which is the primary focus of evolutionary psychologists, encompasses much of what we think of when we think of sexual conflict in nonhuman species, such as sexual cannibalism, grasping and anti-grasping organs, and love darts.

Humans, of course, do not practice sexual cannibalism, we do not have grasping organs on our abdomens, nor do we produce love darts. In humans, traits produced by sexual conflict will often occur in the form of psychological mechanisms. Below, we review evidence for sexual 
conflict as reflected in the design of psychological mechanisms, but before doing so, we discuss the source of sexual conflict in humans.

\section{Why Sexual Conflict?}

Sexual conflict in humans stems from an asymmetry in reproductive biology. Fertilization and gestation occur within females, and this form of sexual reproduction has two consequences that are relevant to sexual conflict in humans: asymmetric parental investment and paternity uncertainty.

Sexual Conflict Associated with Parental Investment

Internal fertilization and gestation produces a discrepancy in parents' investment in offspring (Trivers, 1972). Women's minimum obligatory investment (i.e., minimum amount of parental investment needed to produce offspring) is significantly greater than men's, lasting at least nine months. In comparison, men's obligatory investment can end with a single copulation. This discrepancy in minimal obligatory investment has profound effects on the reproductive (or mating) strategies men and women pursue. Different mating strategies (e.g., being more shortterm oriented or long-term oriented) occur within the sexes (Gangestad \& Simpson, 2000), but are especially pronounced between the sexes (Buss \& Schmitt, 1993; Schaller \& Murray, 2008; Schmitt, 2005). Because men’s minimum obligatory investment is considerably less than women's, the costs associated with fast, indiscriminant mating are much greater for women than for men. Fast, indiscriminant mating could cost a woman substantial time, energy, and resources if conception occurs, whereas reproduction can be much less costly for a man (e.g., Bateman, 1948). Parental investment theory (Trivers, 1972), which states that the sex that makes the larger 
obligatory parental investment will be the more sexually discriminating sex whereas the sex that makes the smaller obligatory parental investment will compete more intensely for access to the higher investing sex, accounts for and predicts much of the sexual conflict observed in humans. For example, parental investment theory predicts that sexual conflict will occur when men and women pursue their optimal mating strategy (i.e., the mating strategy yielding the highest return in reproductive currencies). Without the burden of a large obligatory investment, men (relative to women) would benefit more from short-term, low investment strategies, and when compared to men, women would benefit more, on average, from long-term, high investment strategies. These conflicting strategies account for myriad phenomena, but here we briefly discuss just two: sexual coercion and cognitive biases.

Sexual conflict associated with asymmetric minimum obligatory parental investment explains why, historically and cross-culturally, men are the perpetrators and why women are the victims of sexual coercion and rape. It is yet undetermined whether the psychology associated with rape is an adaptation that was directly selected for or a byproduct of other psychological mechanisms (e.g., McKibbin et al., 2008), but what is known is that sexual coercion is a consequence of conflict over sexual access. It follows from parental investment theory that men will have a stronger desire for sexual variety and will be more sexually persistent, whereas women will be more sexually restricted (Buss \& Schmitt, 1993; Schaller \& Murray, 2008; Schmitt, 2005).

Sexual conflict associated with parental investment also may account for a number of cognitive biases in men and women. Cognitive biases refer to inference-making mechanisms that bias cognition in favor of false positives or false negatives. As predicted by parental investment theory, men consistently overperceive sexual interest in women (e.g., inferring sexual interest 
from a friendly smile) as this error was likely to have been less costly for our male ancestors than underperceiving sexual interest and missing a sexual opportunity (Abbey, 1982; Haselton, 2003; Haselton \& Buss, 2000; Maner et al., 2005). Women, however, are more likely to underperceive commitment in men (e.g., inferring that commitment displays are counterfeit), as this error was likely to have been less costly for our female ancestors than overpreceiving men's commitment and risking desertion (Haselton \& Buss, 2000).

\section{Sexual Conflict Associated with Paternity Uncertainty}

A second potential consequence of internal fertilization and gestation is paternity uncertainty. Due to internal fertilization and gestation, ancestral men could not have been certain that their children were, in fact, genetically their own. Ancestral women, having given birth, had maternity certainty. Internal fertilization and gestation imply that ancestral men could have faced paternity uncertainty, but did they? That is, were ancestral men the victims of cuckoldry—the unwitting investment of resources into genetically unrelated offspring? Even without direct observation of the ancestral environment, the answer is a resounding yes. When considering (a) cross-cultural infidelity and paternal discrepancy rates (reviewed above), (b) the cross-cultural ubiquity and power of male sexual jealousy (e.g., Buss, 2000; Daly et al., 1982), (c) women’s fertile-phase sexuality which functions primarily in the context of extra-pair mating (e.g., Gangestad \& Thornhill, 1998; Gangestad \& Thornhilll, 2008; Penton-Voak et al., 1999), (d) adaptations associated with sperm competition in humans (e.g., Goetz \& Shackelford, 2006; Shackelford \& Goetz, 2007; Shackelford et al., 2007), (e) the matrilateral bias associated with grandparental and avuncular investment (e.g., Euler \& Weitzel, 1996; Gaulin, et al., 1997; Jeon \& Buss, 2007; Michalski \& Shackelford, 2005), and paternity inferences and willingness to invest associated with paternal resemblance (Platek et al., 2002, 2003, 2004, 2005) it becomes 
clear that female infidelity and cuckoldry were recurrent features of our evolutionary history. The evolutionary consequences of female infidelity are many, but here we briefly discuss one: the conflict that occurs during or after mating, known as sperm competition.

Sperm competition is the consequence of males competing for fertilizations (Parker, 1970). If females mate in a way that concurrently places sperm from two or more males in her reproductive tract, this generates several selection pressures on males. If these selection pressures are recurrent throughout a species’ evolutionary history, males may evolve anatomical, physiological, and psychological adaptations to aid their sperm in out-competing rivals' sperm in fertilizations. As discussed above, female infidelity was a recurrent feature of our evolutionary history, and research has begun to uncover men's anatomical, physiological, and psychological adaptations associated with sperm competition.

Anatomical adaptations owed to sperm competition might include men’s relatively large testes and specific features of the penis. The relative size of human testes $(0.08 \%$ of body weight) falls between the relative testes sizes of the highly promiscuous chimpanzee and the polygynous gorilla, suggesting intermediate levels of sperm competition in our evolutionary past. To test the hypothesis that the human penis has been shaped by natural selection to displace semen deposited by other men in the reproductive tract of a woman, Gallup et al. (2003) used artificial genitals and semen to simulate intercourse. The results indicated that artificial phalluses with a glans and coronal ridge that approximated a human penis displaced more simulated semen than did a phallus that did not have such features. When the penis is inserted into the vagina, the frenulum of the coronal ridge makes semen displacement possible by allowing semen to flow back under the penis alongside the frenulum and collect on the anterior of the shaft behind the coronal ridge. 
Regarding physiological adaptations, there is an intriguing possibility that men prudently allocate their sperm according to cues of sperm competition. Baker and Bellis $(1989,1993)$ documented a negative relationship between the proportion of time a couple has spent together since their last copulation and the number of sperm ejaculated at the couple’s next copulation. As the proportion of time a couple spends together since their last copulation decreases, there is a predictable increase in the probability that the man's partner has been inseminated by another man. Additional analyses documented that the proportion of time a couple spent together since their last copulation predicts sperm number ejaculated at the couple's next copulation, but not at the man's next masturbation (Baker \& Bellis, 1993). Also in support of the hypothesis that men adjust their ejaculates in accordance with sperm competition theory, experimental evidence has demonstrated that men viewing images depicting cues to sperm competition produce more competitive ejaculates than men viewing comparable images in which cues to sperm competition are absent (Kilgallon \& Simmons, 2005). Kilgallon and Simmons documented that men produce a higher percentage of motile sperm in their ejaculates after viewing sexually explicit images of two men and one woman (sperm competition images) than after viewing sexually explicit images of three women.

Inspired by Baker and Bellis’s (1989, 1993) demonstration of male physiological adaptations to sperm competition, Shackelford and his colleagues (2002, 2007) documented that men may possess psychological adaptations to decrease the likelihood that a rival man's sperm will fertilize a partner’s ovum. In two independent samples, men who spent a greater proportion of time apart from their partners since the couples’ last copulation-and, therefore, face a higher risk of sperm competition-perceive their partners to be more sexually attractive, are more interested in copulating with their partners, report that their partners are more interested in 
copulating with them, and report greater distress and more sexual persistence in response to their partner's sexual rejection, relative to men who spent a lesser proportion of time apart from their partners. These effects were independent of men's relationship satisfaction, total time since last copulation, and total time spent apart, which rules out several alternative explanations. These perceptual changes may motivate men to copulate as soon as possible with their partners, thereby entering their sperm into competition with any rival sperm that may be present in their partners' reproductive tracts.

The question as to whether sperm competition has been an important selection pressure during human evolution remains somewhat controversial, and further research is needed to establish the extent to which this might be the case. As outlined above, however, there is mounting evidence that aspects of male anatomy, physiology, and psychology may reflect adaptations to sperm competition (see also, Goetz et al., 2008).

\section{Conclusions}

The evolutionary interests of human males and females are certainly asymmetrical, so there is no reason to doubt that sexual conflict occurred throughout our evolutionary history. Indeed, sexual conflict in humans is a growing field of study among evolutionary psychologists, and many researchers have studied conflict over sexual access (e.g., McKibbin et al., 2008) conflict that occurs during and after mating (e.g., Shackelford \& Goetz, 2007), and conflict occurring that occurs after conception (e.g., Anderson et al., 2007), for example.

Arnqvist and Rowe's (2005) reluctance to discuss sexual conflict in humans in their monograph, Sexual Conflict, might be attributable to the different empirical approaches 
employed by behavioral ecologists and evolutionary psychologists. Arnqvist and Rowe outlined six research methods that have been used to document sexual conflict, such as genetic experiments, phenotypic manipulations, experimental evolution, and comparative studies, and only a couple of these are readily applicable to human populations. Evolutionary psychologists are unable to use experimental evolution techniques and genetic engineering to study sexual conflict in humans, for example. They have at their disposal, however, additional methods that are well developed in research with human subjects but that cannot be employed readily by those who study nonhuman animals. Survey methodologies that secure self-reported perceptions and behavioral history provide a useful means to access human cognition and behavior. Methodologies measuring reaction time provide more objective access to perceptual and motivational processes. And more recently, neuroimaging techniques are allowing researchers to study the modular design of the human mind, identifying neural correlates of hypothesized psychological mechanisms. As evolutionary psychologists dedicated to understanding how the human mind has been shaped by selection, we are in a position to test hypotheses about how men's and women's minds have evolved to solve problems generated by the opposite sex.

\section{Acknowledgements}

We would like to thank Joris Koene and members of the Sexual Conflict Symposium at VU University for helpful discussion and comments concerning this line of work. 


\section{References}

Abbey, A. (1982) Sex differences in attributions for friendly behavior: do males misperceive females’ friendliness? J. Pers. Soc. Psychol., 42, 830-838.

Anderson, K.G. (2006) How well does paternity confidence match actual paternity? evidence from worldwide nonpaternity rates. Curr. Anthropol., 48, 511-518.

Anderson, K.G., Kaplan, H. \& Lancaster, J.B. (2007) Confidence of paternity, divorce, and investment in children by Albuquerque men. Evol. Hum. Behav., 28, 1-10.

Arqvist, G. \& Rowe, L. (2005) Sexual Conflict. Princeton University Press, Princeton.

Baker, R.R. \& Bellis, M.A. (1989) Number of sperm in human ejaculates varies in accordance with sperm competition theory. Anim. Behav., 37, 867-869.

Baker, R.R. \& Bellis, M.A. (1993) Human sperm competition: ejaculate adjustment by males and the function of masturbation. Anim. Behav., 46, 861-885.

Bateman, A.J. (1948) Intrasexual selection in Drosophila. Heredity, 2, 349-368.

Bellis, M.A., Hughes, K., Hughes, S. \& Ashton, J.R. (2005) Measuring paternal discrepancy and its public health consequences. J. Epidemiol. Commun. H., 59, 749-754.

Buss, D.M. (1989) Conflict between the sexes: strategic interference and the evocation of anger and upset. J. Pers. Soc. Psychol., 56, 735-747.

Buss, D.M. (2000) The Dangerous Passion. The Free Press, New York.

Buss, D.M. \& Schmitt, D.P. (1993) Sexual Strategies Theory: a contextual evolutionary analysis of human mating. Psychol. Rev., 100, 204-232. 
Cerda-Flores, R.M., Barton, S.A., Marty-Gonzales, L.F., Rivas, R. \& Chakrborty, R. (1999) Estimation of nonpaternity in the Mexican population of Nuevo Leon: a validation study with blood group markers. Am. J. Phys. Anthropol., 109, 281-293.

Daly, M., Wilson, M. \& Weghorst, S.J. (1982) Male sexual jealousy. Ethol. Sociobiol., 3, 11-27.

Euler, H. A. \& Weitzel, B. (1996) Discriminative grandparental solicitude as reproductive strategy. Hum. Nature-Int. Bios., 7, 39-59.

Gallup, G.G., Burch, R.L., Zappieri, M.L., Parvez, R.A., Stockwell, M.L. \& Davis, J.A. (2003) The human penis as a semen displacement device. Evol. Hum. Behav., 24, 277-289.

Gangestad, S.W. \& Simpson, J.A. (2000) The evolution of human mating: trade-offs and strategic pluralism. Behav. Brain Sci., 23, 573-587.

Gangestad, S.W. \& Thornhill, R. (1998) Menstrual cycle variation in women’s preferences for the scent of symmetrical men. P. Roy. Soc. Lond. B Bio., 265, 927-933.

Gangestad, S.W. \& Thornhill, R. (2008) Human oestrus. P. Roy. Soc. Lond. B Bio., 275, 9911000.

Gaulin, S.J.C., McBurney, D.H. \& Brakeman-Wartell, S.L. (1997) Matrilateral biases in the investment of aunts and uncles: a consequence of measure of paternity uncertainty. Hum. Nature-Int. Bios., 8, 139-151.

Goetz, A.T. \& Shackelford, T.K. (2006) Sexual coercion and forced in-pair copulation as sperm competition tactics in humans. Hum. Nature-Int. Bios., 17, 265-282.

Goetz, A.T., Shackelford, T.K., Platek, S.M., Starratt, V.G. \& McKibbin, W.F. (2008) Sperm competition in humans: implications for male sexual psychology, physiology, anatomy, and behavior. Annu. Rev. Sex Res., 18, 1-22. 
Haselton, M.G. (2003) The sexual overperception bias: evidence of a systematic bias in men from a survey of naturally occurring events. J. Res. Pers., 37, 43-47.

Haselton M.G. \& Buss, D.M. (2000) Error management theory: a new perspective on biases in cross-sex mind reading. J. Pers. Soc. Psychol., 78, 81-91.

Jeon, J. \& Buss, D.M. (2007) Altruism towards cousins. P. Roy. Soc. Lond. B Bio., 274, 11811187.

Kilgallon, S.J. \& Simmons, L.W. (2005) Image content influences men’s semen quality. Biol. Lett., 1, 253-255.

Koehler, N. \& Chisholm, J.S. (2007) Early psychosocial stress predicts extra-pair copulations. Evol. Psychol., 5, 184-201.

Maner, J.K., Kenrick, D.T., Neuberg, S.L., Becker, D.V., Robertson, T., Hofer, B., Delton, A., Butner, J. \& Schaller, M. (2005) Functional projection: how fundamental social motives can bias interpersonal perception. J. Pers. Soc. Psychol., 88, 63-78.

McKibbin, W.F., Shackelford, T.K., Goetz, A.T. \& Starratt, V.G. (2008) Why do men rape? an evolutionary psychological perspective. Rev. Gen. Psychol., 12, 86-97.

Michalski, R.L. \& Shackelford, T.K. (2005) Grandparental investment as a function of relational uncertainty and emotional closeness with parents. Hum. Nature-Int. Bios., 16, 293-305.

Parker, G.A. (1970) Sperm competition and its evolutionary consequences in the insects. Biol. Rev., 45, 525-567.

Parker, G.A. (1979) Sexual selection and sexual conflict. In: M.S. Blum \& N.A. Blum (Eds.), Sexual Selection and Reproductive Competition in Insects, pp. 123-166. Academic Press, New York. 
Penton-Voak, I.S., Perrett, D.I., Castles, D.L., Kobayashi, T., Burt, D.M., Murray, L.K. \& Minamisawa, R. (1999) Female preference for male faces changes cyclically. Nature, 399, 741-742.

Platek, S.M., Burch, R.L., Panyavin, I.S., Wasserman, B.H. \& Gallup, G.G. (2002) Reactions to children's faces: resemblance matters more for males than females. Evol. Hum. Behav., 23, 159-166.

Platek, S.M., Critton, S.R., Burch, R.L., Frederick, D.A., Myers, T.E. \& Gallup, G.G. (2003) How much resemblance is enough? sex difference in reactions to resemblance, but not the ability to detect resemblance. Evol. Hum. Behav., 24, 81-87.

Platek, S.M., Raines, D.M., Gallup, G.G., Mohamed, F.B., Thomson, J.W., Myers, T.E., Panyavin, I.S., Levin, S.L., Davis, J.A., Fonteyn, L.C.M. \& Arigo, D.R. (2004) Reactions to children's faces: males are still more affected by resemblance than females are, and so are their brains. Evol. Hum. Behav., 25, 394-405.

Platek, S.M., Keenan, J.P. \& Mohamed, F.B. (2005) Sex differences in neural correlates of child facial resemblance: an event-related fMRI study. NeuroImage, 25, 1336-1344.

Rice, W.R. \& Chippindale, A.K. (2008) Intersexual ontogenetic conflict. J. Evol. Biol., 14, 685693.

Sasse, G., Muller, H., Chakraborty, R. \& Ott, J. (1994) Estimating the frequency of nonpaternity in Switzerland. Hum. Hered., 44, 337-343.

Schaller, M. \& Murray, D.R. (2008) Pathogens, personality, and culture: disease prevalence predicts worldwide variability in sociosexuality, extraversion, and openness to experience. J. Pers. Soc. Psychol., 95, 212-221. 
Schmitt, D.P. (2005) Sociosexuality from Argentina to Zimbabwe: a 48-nation study of sex, culture, and strategies of human mating. Behav. Brain Sci., 28, 247-311.

Shackelford, T.K. \& Goetz, A.T. (2007) Adaptation to sperm competition in humans. Curr. Dir. Psychol. Sci., 16, 47-50.

Shackelford, T.K., Goetz, A.T., McKibbin, W.F. \& Starratt, V.G. (2007) Absence makes the adaptations grow fonder: proportion of time apart from partner, male sexual psychology, and sperm competition in humans (Homo sapiens). J. Comp. Psychol., 121, 214-220.

Shackelford, T.K., LeBlanc, G.J., Weekes-Shackelford, V.A., Bleske-Rechek, A.L., Euler, H.A. \& Hoier, S. (2002) Psychological adaptation to human sperm competition. Evol. Hum. Behav., 23, 123-138.

Smith, R.L. (1984) Human sperm competition. In: R.L. Smith (Ed.), Sperm Competition and the Evolution of Animal Mating Systems, pp. 601-660. Academic Press, New York.

Trivers, R.L. (1972). Parental investment and sexual selection. In: B. Campbell (Ed.), Sexual Selection and the Descent of Man, pp. 136-179. Aldine, Chicago. 